\title{
PENGARUH GAYA KEPEMIMPINAN GEMBALA SIDANG DAN KESEJAHTERAAN TERHADAP MOTIVASI MELAYANI GURU SEKOLAH MINGGU DI GBI JAKARTA TIMUR
}

\author{
Yopie Ndolu', Bobby Kurnia Putrawan ${ }^{2}$ \\ Sekolah Tinggi Teologi Ekumene Jakarta ${ }^{1}$ \\ Sekolah Tinggi Teologi STAPIN Majalengka ${ }^{2}$
}

\author{
Korespondensi: \\ bkputrawan@gmail.com \\ Histori: \\ Diserahkan 6 Februari 2021, \\ dipublikasikan 15 Maret 2021 \\ DOI: \\ Keywords: leadership, pastors, \\ welfare serving, serving \\ motivation \\ Kata kunci: kepemimpinan, \\ gembala sidang, kesejahteraan \\ melayani, motivasi melayani

\section{(c) ()ㅇㅇ dipublikasikan di bawah NonCommercial-ShareAlike 4.0 International License} \\ Creative Commons Attribution-
}

Abstract. This study aims to determine the relationship between the pastor's leadership style and the welfare of serving on the motivation to serve Sunday school teachers in GBI sector 1, East Jakarta. The method used in this study is a correlational survey. The research sample was 35 people who were taken using a simple random sampling technique. The instrument used in collecting data was a questionnaire. The validity test used the Pearson Product Moment formula, and the reliability was analysed using the Alpha Cronbach formula. Based on testing the significance of the multiple correlation coefficient, the coefficient is 46.911 with a P-value of 0.000 . Because the $P$-value is less than 0.05 , it is very significant, then $\mathrm{HO}$ is rejected, and $\mathrm{H} 1$ is accepted. It can be concluded that there is a positive and significant relationship between the leadership style of the pastor and the welfare of serving together with the motivation to serve with a multiple correlation coefficient (Ry.12) of 0.864. The coefficient of determination (R2y.12) is 0.730 , which means that $73.00 \%$ of the variance in serving motivation can be explained by the pastor's leadership style and the welfare of performing together.

\begin{abstract}
Abstrak. Penelitian ini bertujuan untuk mengetahui hubungan antara gaya kepemimpinan gembala sidang dan kesejahteraan melayani terhadap motivasi melayani guru sekolah minggu di GBI sektor 1 Jakarta Timur. Metode yang digunakan dalam penelitian ini adalah survei korelasional. Sampel penelitian 35 orang yang diambil menggunakan teknik simple random sampling. Instrumen yang digunakan dalam mengumpulkan data adalah kuesioner. Pengujian validitas menggunakan rumus Pearson Product Moment dan reliabilitasnya dianalisis dengan rumus Alpha Cronbach. Berdasarkan hasil pengujian signifikansi koefisien korelasi ganda diperoleh koefisien 46,911 dengan $P$-value sebesar 0,000 . Oleh karena $P$-value lebih kecil dari 0,05 yang berarti sangat signifikan maka $\mathrm{H}_{0}$ ditolak dan $\mathrm{H}_{1}$ diterima. Dapat disimpulkan terdapat hubungan positif dan signifikan antara gaya kepemimpinan gembala sidang dan kesejahteraan melayani secara bersama-sama dengan motivasi melayani dengan koefisien korelasi ganda $\left(R_{y} .12\right)$ sebesar 0,864 . Koefisien determinansi $\left(R^{2}\right.$ y.12) diperoleh sebesar 0,730 memiliki arti bahwa $73,00 \%$ variansi motivasi melayani dapat dijelaskan oleh gaya kepemimpinan gembala sidang dan kesejahteraan melayani secara bersamasama.
\end{abstract}




\section{PENDAHULUAN}

Pendidikan anak seringkali terabaikan oleh sebagian orang tua masa kini. Hal ini terlihat dari semakin bertambahnya anak seperti tawuran, penyalahgunaan narkotika, pergaulan bebas, penyalahgunaan media, dll. Bahkan ada yang bunuh diri ketika merasa gagal dalam mendapatkan keinginannya.

Guru Sekolah Minggu (SM) berperan penting dalam mengajar, mendidik dan menerjemahkan Firman Tuhan kepada anak-anak. Guru juga berperan membimbing anak agar mempunyai karakter yang baik. Pembimbingan sangat penting dalam pembentukan karakter anak didik dalam berprilaku yang lebih baik dan bertanggung jawab (Kristiono dan Perdana 2019).

Untuk bisa melayani anak dengan baik, guru SM perlu memiliki motivasi yang kuat. Motivasi yang kuat akan membawa guru SM setia dalam pelayanan seperti yang diteladankan Yesus. Yesus sangat setia dalam pelayan-Nya. Walaupun berjalan kaki dari suatu desa ke desa yang lain semua dilakukan dengan hati yang tulus, tanpa bersungut-sungut (Kristiono dan Perdana 2019).

Motivasi merupakan proses internal yang mendasari dan mengarahkan perilaku manusia (Santrock 2008; Woolfolk 2002). Motivasi juga adalah pendorong atau kekuatan seseorang untuk berupaya mencapai tujuan (Hamalik 2008; Hellriegel dan Slocum 1979; Koontz dan Weihrich 1997). Gage dan Berliner menyatakan bahwa motivasi memiliki 
3 (tiga) komponen yaitu: (1) dorongan, energi yang menyebabkan orang bertindak (2) arahan, yang meliputi perilaku seseorang. (3) pemeliharahan, perilaku yang ditunjukan melalui keinginan untuk terus berusaha sampai meraih sasaran tertentu (Gage dan Berliner 1998).

Motivasi didorong juga oleh kebutuhan manusia. Menurut teori Maslow, kebutuhan manusia memiliki 5 hirarki meliputi: 1) kebutuhan fisiologis, 2) kebutuhan akan rasa aman, 3) kebutuhan sosial, 4) kebutuhan akan penghargaan, 5) kebutuhan aktualisasi diri. Kebutuhankebutuhan tersebut oleh Maslow dirumuskan secara hirarkis dari mulai yang terendah sampai yang tertinggi atau pada kebutuhan psikologis sampai pada kebutuhan aktualisasi diri (dalam Robbins 2006). Adelfer menajamkan hirarki Maslow dalam tiga kelompok, yang dinyatakan sebagai keberadaan, keterkaitan, dan pertumbuhan (existence, relatednes, and growth ) yang dikenal dengan teori ERG (Adelfer 1972).

Menurut teori kebutuhan McClelland bahwa perubahan perilaku manusia terdiri dari tiga kebutuhan pokok yang mendorong motivasi, yaitu: 1) berprestasi (need for achieviement), 2) berafiliasi (need for affiliation) dan 3) kekuasaan (need for power). Dari ketiga hal tersebut, penelitian ini hanya difokuskan pada motivasi berprestasi. Menurut McClelland motivasi berprestasi adalah dorongan untuk mengerjakan sesuatu untuk jadi lebih baik atau lebih efisien dari sebelumnya. Motivasi berprestasi tercermin dari perilaku seseorang yang selalu mengarahkan pada standar keunggulan (standard of exellence). Terdapat tiga karakteristik umum dari 
orang yang memiliki motivasi berprestasi, yaitu: (1) memiliki rasa tanggung jawab yang tinggi terhadap pelaksanaan tugas, 2) cenderung menetapkan tingkat kesulitan tugas moderat dan menghitung resiko, dan 3) memiliki keinginan yang kuat untuk memperoleh umpan balik dari pekerjaannya (McClelland 1999). Motivasi pelayanan yang besar sebagai penggerak yang kuat menjadikan seorang guru sekolah minggu dapat melakukan tanggung jawab pelayanannya dengan baik.

Menurut Uno motivasi seseorang juga dipengaruhi oleh perasaan seberapa baik dirinya diperlakukan dibandingkan orang lain. Apabila seseorang merasa bahwa dirinya diperlakukan tidak sebaik perlakukan terhadap orang lain, kemungkinan besar orang tersebut tidak terdorong untuk menyajikan kinerja yang baik (Uno 2007). Sebab itu terkait dengan pelayanan guru SM, dapat dikatakan bahwa guru SM akan memiliki motivasi yang kuat apabila kebutuhannya terpenuhi.

Selain terpenuhinya kebutuhan, motivasi pelayanan guru SM dipengaruhi juga oleh gaya kepemimpinan gembala sidang di gereja tempat mereka melayani. Pemimpin yang ramah dan perhatian akan memotivasi guru sekolah minggu dalam mengajar. Gembala sidang harus mendorong tumbuhnya motivasi melayani yang baik guru SMU.

Terry mendefinisikan kepemimpinan sebagai hubungan yang ada dalam diri seorang pemimpin, mempengaruhi orang-orang lain untuk bekerjasama secara sadar untuk mencapai tujuan (Terry 1972). Kepemimpinan berkenaan dengan penggunaan kekuasaan dan 
pembuatan keputusan-keputusan (Rosmiati dan Kurniadi 2008). Kepemimpinan adalah penggunaan pengaruh dalam memotivasi orangorang mencapai tujuan tertentu (Gibson 1988). Kepemimpinan merupakan interaksi yang dinamis antara pemimpin dengan yang dipimpin (Owens 1995; Bulan dan Hasibuan 2019).

Seorang pemimpin sejati harus menyakini akan panggilan Ilahi dalam hidupnya, sehingga dalam menjalankan tugas dan tanggungjawabnya ia tetap fokus terhadap apa yang menjadi perintah Ilahi. Karena pemimpin yang tidak terpanggil, biasanya akan melarikan diri dari tanggung jawabnya ketika ada masalah yang serius (Bulan dan Hasibuan 2019). Pemimpin harus melihat dan menyadari misi yang Tuhan percayakan. Tanpa misi, kepemimpinan menjadi tanpa arah. Dalam tugas kepemimpinan, seorang pemimpin harus jelas dengan misinya sehingga ia dapat mengarahkan dan membawa pengikutnya berjalan bersamanya sampai pada tujuan misi tersebut.

Gaya kepemimpinan yang mendatangkan keberhasilan dan pertumbuhan bagi gereja-Nya adalah seorang pemimpin yang memberi diri. Seorang pemimpin dapat dikatakan sebagai seorang penentu berkembang atau tidaknya sebuah gereja. Seorang pemimpin juga merupakan seorang yang aktifitasnya adalah mempengaruhi orang-orang yang dipimpinnya untuk diarahkan demi tercapainya arah dan tujuan organisasi yang dipimpinnya. Dalam hal ini, organisasi itu adalah gereja itu sendiri. Karenanya ia dituntut untuk tidak saja memiliki pandangan 
yang jelas dan terarah pada visi dan misi yang dimilikinya, tetapi juga dituntut untuk memiliki wawasan yang luas, intelektual yang tinggi, cara pandang yang bersifat surgawi dan alkitabiah dan bersikap arif terhadap yang dipimpinnya.

Rosmiati dan Kurniadi menyatakan terdapat empat gaya atau tipe kepemimpinan pendidikan, yaitu otoriter, Laissez-fair, demokratis dan pseudo-demokratis. Dalam kepemimpinan otoriter, pemimpin bertindak sebagai ditaktor terhadap anggota-anggotanya. Dalam kepemimpinan Laissez-faire pemimpin memberikan kebebasan kepada anggota untuk berbuat sekehendaknya. Pemimpin sama sekali tidak melakukan kontrol dan koreksi terhadap pekerjaan bawahannya. Pembagian tugas dan kerja sepenuhnya diserahkan kepada bawahan tanpa petunjuk dan saran-saran dari pemimpin. Dalam kepemimpinan demokrasi pemimpin berusaha mestimulasi anggota-anggotanya untuk bekerja secara produktif untuk mencapai tujuan bersama. Pemimpin dalam tipe ini dalam tindakan dan usahanya selalu berpangkal pada kepentingan dan kebutuhan organisasi serta mempertimbangkan kemampuan dan kesanggupan para anggotanya. Dalam kepemimpinan pseudo-demokratis, pemimpin tampaknya bersikap demokratis padahal sebenarnya dirinya bersikap otoriter (Rosmiati dan Kurniadi 2008).

Perjanjian Baru sendiri dalam hal ini memberi contoh yang konkret akan seorang pemimpin yang memenuhi seluruh standar karakter kepemimpinan, yaitu Yesus. la adalah seorang pemimpin yang tidak saja 
memiliki pandangan maupun wawasan serta visi dan misi yang jelas, tetapi la dapat melakukan dengan tepat apa yang menjadi target kepemimpinan-Nya. la juga adalah seorang pemimpin yang merelakan segala yang dimiliki-Nya bagi orang-orang yang berada di bawah pimpinan-Nya, termasuk di dalamnya nyawa-Nya sendri. Dengan kata lain dalam hal ini, gaya kepemimpinan Kristen yang membuat gereja bertumbuh adalah gaya kepemimpinan yang bersifat memberi diri dengan tulus tanpa keraguan dalam hatinya.

Menurut Lewis, Lippit dan White terdapat tiga gaya kepemimpinan yaitu: gaya kepemimpinan otoriter, gaya kepemimpinan demokratis atau partisipatif dan gaya kepemimpinan Laissez-faire (lepas-kendali). Gaya kepemimpinan otoriter adalah seorang pemimpin dalam menentukan kebijakan kelompok atau membuat keputusan tanpa berkonsultasi dengan atau memastikan persetujuan daripada anggotanya. Pemimpin ini bersifat impersonal. Komunikasi mengalir dari pemimpin ke pemimpin, tetapi jarang mengalir dari anggota ke anggota. Pemimpin otoriter berusaha untuk meminimumkan komunikasi antar kelompok, sehingga membuat peran pemimpin menjadi lebih penting (Bulan dan Hasibuan 2019). Jadi pemimpin otoriter mengasumsikan tanggungjawab terbesar bagi perkembangan kelompok dan menginginkan tidak adanya campur tangan dari anggotanya. Anggota hendaknya menerima keputusan yang telah diputuskan oleh pemimpin (Devito 1997). Kepribadian setiap pemimpin sendiri berarti dirinya yang menjadi penjaga dalam bertugas memelihara 
dan mengawasi orang-orang yang bernaung di bawah komunitasnya atau kelompoknya. Karenanya dalam hal ini kepemimpinan setiap pemimpin dapat diartikan sebagai suatu upaya yang nyata dalam cara memimpin yang ditunjukan oleh masing-masing untuk memberikan bimbingan atau tuntunan pada para anggota kelompoknyanya, maupun kemampuan untuk memaksimalkan setiap potensi yang ada untuk mencapai tujuan gereja tersebut. Dalam hal ini kepemimpinan tim dapat menggerakan fungsi manajemen di mana merupakan hal yang sangat penting untuk mencapai tujuan organisasi.

Likert merancang 4 sistem kepemimpinan, yaitu: Sistem 1, pemimpin bergaya otokrasi dan memiliki sedikit kepercayaan kepada bawahan. Sistem 2, pemimpin bergaya otokrasi yang berhati baik. Sistem 3, gaya kepemimpinan manajer konsultatif. Sistem 4, pemimpin yang bergaya kelompok partisipatif. Pada sistem 4, pemimpin mempunyai kepercayaan yang penuh terhadap bawahannya. Dalam setiap persoalan, dirinya mengandalkan bawahan untuk mendapatkan gagasan-gagasan, pendapat-pendapat serta mempunyai niat untuk menggunakan pendapat bawahan secara konstruktif. Pemimpin memberikan penghargaan yang bersifat ekonomis berdasarkan partisipasi bawahannya dan keterlibatannya pada setiap urusan, terutama dalam penentuan tujuan bersama dan penilaian kemajuan pencapaian tujuan tersebut (dalam Thoha 1994). 
Berdasarkan teori-teori yang telah diuraikan, maka yang dimaksud dengan gaya kepemimpinan gembala sidang dalam penelitian ini adalah suatu cara yang ditetapkan dan digunakan gembala sidang sebagai pemimpin gereja dalam upaya mempengaruhi dan menggerakkan perilaku para guru SM untuk melaksanakan tugas pekerjaannya dengan penuh tanggungjawabnya dalam mewujudkan tujuan pelayanan yang telah ditetapkan dapat tercapai secara efektif dan efisien.

Gaya kepemimpinan tersebut diukur dengan beberapa gaya yaitu,

1) Gaya kepemimpinan demokrasi atau partisipatif dengan indikatorindikator: (a) berkonsultasi dengan bawahan, dan (b) menggunakan saran yang diberikan bawahan sebelum mengambil keputusan;

2) kepemimpinan Laissez-faire dengan indikator-indikator: a) pembagian tugas dan kerja sepenuhnya diserahkan kepada bawahan tanpa petunjuk dan saran, b) pemimpin tidak melakukan kontrol dan koreksi terhadap pekerjaan bawahannya;

3) kepemimpinan melayani dengan indikator-indikator: a) Menunjukkan kepedulian dan empati sebagai bentuk kasih, b) Rela berkorban bagi bawahan, dan c) memberikan keteladanan;

4) Gaya kepemimpinan otoriter dengan indikator-indikator: (a) memaksanakan kehendak kepada bawahan, (b) membuat keputusan tanpa berkonsultasi dengan bawahan;

5) Gaya kepemimpinan delegatif dengan indikator-indikator: a) memberikan kepercayaan penuh kepada bawahan untuk memutuskan 
perkara-perkara yang dapat diputuskan, b) mempersiapkan para pemimpin baru.

Hal berikut yang dapat dianggap mempengaruhi motivasi guru SM dalam melayani adalah pemenuhan kesejahteraan. Kesejahteraan, menurut Wilensky dan Lebeaux, adalah sistem yang terorganisasi dari pelayanan-pelayanan dan lembaga-lembaga sosial, yang dirancang untuk membantu individu dan kelompok agar mencapai tingkat hidup dan kesehatan yang memuaskan. Maksudnya agar tercipta hubungan personal dan sosial yang memberi kesempatan kepada individu mengembangkan kemampuannya seluasnya dan meningkatkan kesejahteraan sesuai dengan kebutuhan-kebutuhan masyarakat (Wilensky dan Lebeaux 1965).

Pemberian kesejahteraan bertujuan untuk: (1) meningkatkan motivasi kerja guru, (2) meningkatkan kualitas profesional, (3) memenuhi pencapaian kebutuhan, (4) meningkatkan rasa percaya diri bagi profesi guru, (5) meningkatkan status sosial kehidupan pribadi dan keluarga, (6) memberi pengakuan dan interaksi sosial yang lebih baik, dan (7) dapat membangun perencanaan masa depan (Surya 2004). Kesejahteraan yang diberikan kepada setiap guru akan berdampak baik terhadap motivasinya dalam melakukan fungsi dan tanggung jawab yang diberikan. Guru yang dijamin kesejahteraannya akan merasa diperhatikan dan dihargai dalam profesi yang dilakukannya. Hal ini juga terkait dengan 
bagaimana seorang guru dapat dihargai di lingkungan di mana dirinya berada dengan status sosial yang lebih baik.

Mulyasa menyatakan bahwa kesejahteraan guru dapat diukur dari gaji dan insentif yang diperoleh. Rendahnya kesejahteraan guru dapat mempengaruhi kinerjanya, semangat pengabdian, dan juga upaya pengembangan profesionalitasnya (Mulyasa 2007). Pemenuhan kebutuhan yang sesungguhnya harus memenuhi standar hidup kelayakan yang baik. Dalam pemenuhan kesejahteraan perlu memperhatikan banyak hal yang dapat meningkatkan kualitas hipup layak dari seorang guru. Hal ini sangat mempengaruhi motivasi guru untuk mengajar dengan lebih baik.

Kesejahteraan guru adalah keadaan sejahtera yang dialami oleh guru dari pemenuhan kebutuhannya atas profesi yang dilaksanakan guna meningkatkan kualitas melayani sesuai dengan profesinya berupa imbal jasa, rasa aman, kondisi tempat pelayanan, dan pengembangan diri dalam pelayanan. Dimensi-dimensi di atas terdiri dari indikator, yaitu:

1) Dimensi Imbal jasa dengan indikator-indikator: a) Pemberian upah/persembahan kasih, dan b) insentif;

2) Dimensi rasa aman dengan indikator-indikator: a) Suasana pelayanan yang kondusif, dan b) Perwujudan kerja sama antara Guru Sekolah Minggu.

3) Dimensi kondisi pelayanan dengan indikator-indikator: a) Ketersediaan Sarana dan Prasarana yang memadai, dan b) Mendorong semangat pengabdian. 
4) Dimensi pengembangan diri dalam pelayanan dengan indikatorindikator: a) Kesempatan untuk mengikuti pelatihan dan pendidikan sesuai bidang pelayanan, b) Penghargaan terhadap tugas

Dari uraian di atas dapat dikatakan bahwa ada hubungan antara antara gaya kepemimpinan gembala sidang dan kesejahteraan melayani terhadap motivasi melayani guru sekolah minggu. Penelitian ini bertujuan untuk mengetahui hubungan antara gaya kepemimpinan gembala sidang dan kesejahteraan melayani terhadap motivasi melayani guru sekolah minggu tersebut di Gereja Betel Indonesia sektor 1 Jakarta Timur.

\section{METODE PENELITIAN}

Penelitian ini dilaksanakan di Geraja Bethel Indonesia (GBI) Sektor 1 Jakarta Timur. Populasi target dalam penelitian ini adalah seluruh guru sekolah minggu di GBI Sektor 1 Jakarta Timur sebanyak 30 orang. Untuk memperoleh sampel yang representatif, maka dalam penelitian ini menggunaan teknik multistage random sampling, yaitu pemilihan atau penentuan sampel secara bertahap.

Adapun dalam pengolahan data dalam penelitian ini menggunakan teknik analisis deskriptif dan analisis inferensial. Analisis deskriptif dilakukan untuk mencari koefisien mean, median, modus, baku simpangan, varians, pembuatan distribusi frekuensi, dan histogram dari skor setiap variabel penelitian.

Analisis inferensial dalam penelitian ini digunakan dengan tujuan agar hasil penelitian dapat dibuat kesimpulan yang dapat digeneralisasi 
dari pengujian hipotesis yang diajukan. Sebelum dilakukan pengujian hipotesis, dilakukan terlebih dahulu uji persyaratan meliputi uji normalitas, dan linearitas regresi. Tujuan melakukan uji normalitas adalah untuk mengetahui apakah data dari masing-masing variabel bersifat normal. Sedangkan linearitas regresi untuk mengetahui apakah persamaan regresinya berbentuk linear.

\section{HASIL PENELITIAN}

Hasil analisis data menunjukan bahwa terdapat hubungan yang positif dan signifikan gaya kepemimpinan gembala sidang dan kesejahteraan melayani secara bersama-sama dan parsial terhadap motivasi melayani. Berdasarkan hasil pengujian signifikansi koefisien korelasi ganda diperoleh koefisien 46,911 dengan $P$-value sebesar 0,000. Oleh karena $P$-value lebih kecil dari 0,05 yang berarti sangat signifikan maka $\mathrm{H}_{0}$ ditolak dan $\mathrm{H}_{1}$ diterima. Dengan demikian dapat disimpulkan bahwa terdapat hubungan positif dan signifikan antara gaya kepemimpinan gembala sidang dan kesejahteraan melayani secara bersama-sama dengan motivasi melayani dengan koefisien korelasi ganda ( $\left.R_{y .12}\right)$ sebesar 0,864 . Koefisien determinansi $\left(R^{2} y .12\right)$ diperoleh sebesar 0,730 memiliki arti bahwa $73,00 \%$ variansi motivasi melayani dapat dijelaskan oleh gaya kepemimpinan gembala sidang dan kesejahteraan melayani secara bersama-sama. Sedangkan sisanya sebesar $27,00 \%$ dipengaruhi variabel lainnya yang tidak diteliti. 


\section{PEMBAHASAN}

Gaya kepemimpinan seorang gembala sidang merupakan faktor yang kuat dalam mewujudkan motivasi melayani yang baik. Dalam hubungan gaya kepemimpinannya seorang gembala sidang harus memiliki kemampuan dalam memotivasi guru sekolah minggu dalam melayani sehingga dalam mengajar dirinya dapat bertanggungjawab melaksanakan setiap tugas dan kepercayaan yang dipercayakan untuk dikerjakan. Dengan demikian, diduga bahwa terdapat hubungan gaya kepemimpinan gembala sidang dengan motivasi melayani guru sekolah minggu. Hubungan gaya kepemimpinan yang baik akan semakin meningkatkan motivasi melayani guru sekolah minggu dalam menyelesaikan tugas mengajar sesuai kebutuhan anak didiknya.

Kesejahteraan merupakan pendorong seorang guru dalam melaksanakan tugas pelayanannya dengan baik. Kesejahteraan mendukung guru dalam mewujudkan proses pembelajaran. Hal ini terkait dengan bagaimana upaya guru dalam melakukan cara dan strategi mengajar yang dapat dimengerti oleh anak didik. Dengan demikian, kesejahteraan melayani yang terpenuhi secara baik akan mempengaruhi motivasi melayani yang berkualitas. Dengan demikian, diduga bahwa terdapat hubungan kesejahteraan melayani dengan motivasi melayani guru sekolah minggu. Semakin baik guru mendapatkan perhatian dalam hal kesejahteraan sehingga kebutuhannya dapat terpenuhi, maka akan meningkatkan motivasinya dalam melayani dan mengajar semakin baik. 
Gaya kepemimpinan gembala sidang dan kesejahteraan dapat secara bersama memberi hubungan yang kuat dengan motivasi melayani guru sekolah minggu. Dalam kaitan motivasi melayani terdapat banyak faktor pendukung yang menjadikan proses mengajar yang dilakukan guru dapat mencapai hasil maksimal. Dari banyaknya faktor pendukung yang dapat mewujudkan dan menggerakkan motivasi seorang guru sekolah minggu dalam melayani maka, gaya kepemimpinan gembala sidang dan kesejahteraan memberi peran yang besar. Dengan demikian, diduga bahwa motivasi melayani guru sekolah minggu dipengaruhi adanya hubungan antara gaya kepemimpinan gembala sidang dan kesejahteraan melayani secara bersama menjadi pendorong kuat. Motivasi dalam melayani guru sekolah minggu akan berdampak positif dalam kualitas mengajar dan hasil dari pembelajaran tersebut.

\section{KESIMPULAN}

Kesimpulan dari tulisan ini adalah bahwa gaya kepemimpinan dan kesejahteraan yang diberikan oleh gembala sidang berpengaruh secara positif dan signifikan terhadap motivasi melayani guru sekolah minggu di GBI sektor 1 Jakarta Timur. Dengan demikian maka untuk meningkatkan motivasi guru sekolah dalam pelayanan perlu diperhatikan kesejahteraan mereka dan juga gaya pendampingan yang diberikan oleh gembala sidang. 


\section{DAFTAR PUSTAKA}

Adelfer, Clayton P. 1972. Existence, Relaednes and Growth. New York: Collier MacMillan.

Bulan, Susanti Embong, dan Patricia Diana Hasibuan. 2019. "Kepemimpinan Dalam Gereja Katolik Paroki Ignatius Loyola Dan Huria Kristen Batak Protestan Setiabudi Menuju Persatuan." QUAERENS: Journal of Theology and Christianity Studies 1 (2): 11121. https://doi.org/10.46362/quaerens.v1i2.5.

Devito, Jaseph A. 1997. Komunikasi antar Manusia. Jakarta: Professional Book.

Gage, L. N., dan David C. Berliner. 1998. Educational Psychology. Boston: Houghton Mifflin Company.

Hamalik, Oemar. 2008. Kurikulum dan Pembelajaran. Jakarta: Bumi Aksara.

Hellriegel, Don, dan John W. Slocum. 1979. Organization Behaviour. Palo Alto: South Western College Publishing.

Koontz, Harold, dan Hainz Weihrich. 1997. Management. New York: McGraw-Hill Books Company.

Kristiono, Tanto, dan Deo Putra Perdana. 2019. "Hambatan Guru dan Pelayanan Sekolah Minggu di Gereja Kristen Jawa Jebres Surakarta." JURNAL TEOLOGI GRACIA DEO 1 (2): 90-100. https://doi.org/10.46929/graciadeo.v1i2.9.

McClelland, David. 1999. Motivational Productivity Management, A Practical Handbook. Geneva: ILO.

Mulyasa, E. 2007. Standar Kompetensi Dan Sertifikasi Guru. Bandung: Rosdakarya.

Owens, Robert G. 1995. Organization Behavior in Education. Boston: Allyn and Bacon.

Robbins, Stephen P. 2006. Organization Behavior, Concepts, Controvercies, and Applications. Jakarta: PT. Bhuana IImu Populer.

Rosmiati, Taty, dan Dedy Achmad Kurniadi. 2008. "Kepemimpinan Pendidikan." In Manajemen Pendidikan. Bandung: Alfabeta.

Santrock, John. W. 2008. Educational Psychology. Boston: McGraw-Hill.

Surya, Mohammad. 2004. Psikologi Pembelajaran dan Pengajaran. Bandung: Pustaka Bani Quraisy.

Terry, Georger R. 1972. Principles of Management. llionois: Homewood.

Thoha, Miftah. 1994. Kepemimpinan Dalam Manajemen. Jakarta: Rajawali. 
Uno, Hamzah B. 2007. Teori Motivasi dan Pengukurannya Analisis di Bidang Pendidikan. Jakarta: Bumi Aksara.

Wilensky, Harold, dan Charles N. Lebeaux. 1965. Industrial Society and Social Welfare. New York: The Free Press.

Woolfolk, Anita E. 2002. Educational Psychology. Boston: Allyn and Bacon. 